\title{
College Students' Interpersonal Communication from the Perspective of Social Exchange Theory

\author{
Shan $\mathrm{MAO}^{1, *}$, Wen-bo $\mathrm{YANG}^{2}$
}

${ }^{1}$ Law and politics department, North China Electric Power University, Baoding, Hebei, China

${ }^{2}$ North China Electric Power University, Baoding, Hebei, China

${ }^{*}$ Corresponding author

Keywords: College Students; Interpersonal Communication; Social Exchange Theory.

\begin{abstract}
Adolescent college students are in a period of rapid growth of psychology and physiology. They are separated from the original family and participate in collective life for the first time, making them one of the most active groups of interpersonal communication, which affects the personality and socialization of college students. From the theoretical perspective of social exchange theory, analyzing the interpersonal communication mode of college students plays an important role in discovering and solving the problems in college students' interpersonal communication. Relying on social exchange theory, this paper proposes improvement strategies from four aspects: successful propositions, stimulating propositions, satisfying propositions and value propositions, promoting college students to build stable interpersonal relationships, and promoting the normal development of interpersonal communication.
\end{abstract}

\section{Introduction}

Interpersonal relationship refers to the psychological relationship formed by people in the process of mutual interaction, including kinship, friend relationship, classmate relationship, teacher-student relationship, employment relationship, comrade-in-arm relationship, colleague relationship, as well as leading and being led relationship. The concept was first established in 1933 by Professor Mayo of Harvard University. The construction of interpersonal relationships is mainly characterized by interpersonal relationships. Sociology defines interpersonal communication as the process by which people establish interpersonal relationships in the process of production or living activities.

Young college students are in a period of rapid growth and maturity of psychology and physiology. At this stage, the group tries and gradually breaks away from the original family and turns into collective life. The scope of interpersonal communication and the middle school period are limited to schools or classes. Physiology and psychology tend to mature and make them curious about interpersonal relationships, making them one of the most active groups of interpersonal interactions. In China, contemporary college students are in a period of rapid social development. Political, economic, and cultural aspects are undergoing changes, and the concept, behavior, and methods of interpersonal communication among college students have been branded in the times [1]. Therefore, understanding the characteristics of interpersonal communication of college students and analyzing their interpersonal communication mode are of great significance for college students to adapt to the changes of the times and develop healthy interpersonal relationships.

As an important school in Western sociological theory, social exchange theory introduces the concepts of reciprocity and exchange in economics research into sociology under the influence of classical utilitarian economics and behavioral psychology. Explaining people's own interactive behavior plays an important role. Based on this, this paper uses social exchange theory as a theoretical perspective to explain and analyze the current situation of interpersonal communication among college students, explain the problems in interpersonal communication and propose countermeasures, thus establishing college students to build a healthy, harmonious and stable interpersonal relationship network and promoting the positive development of interpersonal communication. 


\section{Types and Features of Interpersonal Communication Among College Students}

From birth to death, interpersonal relationships have always been a core part of life experience. Interpersonal relationship refers to the direct psychological relationship formed between people in communication, which is mainly reflected in psychological preference and disgust, that is, the psychological distance is far and near [2]. Interpersonal communication is the external manifestation and concrete process of constructing this distance. The essence of the interpersonal relationship construction of college students can be regarded as an exchange behavior, which is embodied in the emotional exchange and material exchange between multiple behavioral individuals or groups such as classmates, roommates (friends), close companions, teachers and student cadres. The analysis of college students' interpersonal communication based on social exchange theory has certain explanatory significance. Therefore, the related research conducted by the academic circles is not rare.

First of all, the interpersonal relationship of college students is generally divided into four types: intimate peer relationship, relationship with student cadres, dormitory relationship and teacher-student relationship.

Intimate peer relationship, that is, love relationship, college students' love motivation is largely influenced by the values and behaviors of their peers. They often produce a desire for love under the invisible pressure of the surrounding environment and group, that is, social interaction needs. Social exchange theory believes that the establishment of intimate relationship between men and women is an extreme situation of internal attraction. In addition to the special features of exchanged rewards, love relationship is the basic law that satisfies the general social exchange behavior.

In the interpersonal communication between college students and student cadres, because the positions of student cadres and community leaders are scarce resources among the college students, some work of the students who are responsible for these positions will become a problem of power and exchange. The generation of power needs to have certain resources, that is to say, it has the resources to let others serve themselves to obtain the obedience of others. The student cadres have special power and status in the entire college student group, and therefore apply to social exchange.

Teacher-student relationship is one of the most important parts of college students' main interpersonal relationship. The correct choice of communication style is very important. In the university campus, the teacher provides intellectual support to the students to obtain the respect of the students, but it is different from the status of the middle school teacher is absolutely authoritative. Teachers and students often appear as cooperative relationships in the university campus, which is more suitable for mutual exchange and mutual benefit.

Dormitory is the smallest unit of university life, so the dormitory relationship also has a certain specialty. The dormitory relationship of college students is often in an invisible exchange behavior, including material exchange and emotional exchange. This feature is also in line with the perspective of social exchange theory [3].

From the analysis of the above four interpersonal relationships, we can find that there are some remarkable features in the interpersonal communication of contemporary college students:

The first is utilitarianism. In the process of establishing interpersonal relationships, college students are increasingly valued what resources they can bring to themselves, and thus produce purposeful interactions. This feature is particularly evident in the interaction between college students and teachers and student cadres.

The second is shallow. In the current era of digitalization and informationization, college students as testers and pioneers of new technologies and new ideas are often more likely to use the Internet for interpersonal communication, and their communication is more efficient and convenient. Under this background, the level of interpersonal communication of college students is often lower, only staying at a relatively shallow level, limited by geographical and utilitarian.

The third is diversity. There are often many ways of interpersonal communication among college students, such as encounters (such as conversations), formal contacts (such as classmates), virtual interactions (such as paying netizens) and so on, emotional exchanges (such as falling in love) and Instrumental interactions (such as trusteeship). They are intertwined in form and varied. 
In the process of interpersonal communication among college students, there are often many problems. Self-interest, autism, and inferiority are three of the most prominent problems [4]. It can be seen from the above that the social exchange theory can be used to explain the interpersonal communication process of college students and some specific situations in it, and it plays an important role in analyzing the interpersonal communication mode of college students. However, the existing research is often only a comprehensive perspective of social exchange theory. It analyzes the interpersonal interactions of college students, but lacks exploration of the problems and solutions that arise, and its era is also slightly backward. Can we use social exchange theory as the theoretical basis to propose a solution path for college students' interpersonal communication problems? In the next section, this article will focus on this and conduct a detailed discussion.

\section{Research of Social Exchange Theory}

Social exchange theory is a sociological theory that began to emerge from the United States after the Second World War. Its roots are psychological behaviorism, economic functionalism, and sociological structuralism. Representatives include Homans, Blau and Coleman.

Homans's theory is greatly influenced by behavioral psychology and economics. The six basic propositions are the core propositions, which are successful proposition, stimulating proposition, value proposition, deprivation-satisfaction proposition, attack-consistent proposition and rational proposition. According to Homans, these propositions are a whole of each other. Although a single proposition can only partially explain human behavior, the whole proposition system can fully explain the social structure [5].

Blau and Homans have different theories. Blau believed that from the micro to the macro, the process of exchange was the same, but it had become more complicated. The subject of exchange has expanded from individuals to groups and social organizations. The nature of exchange has also expanded from direct to indirect. And the process of social structure becomes a process that is constrained by social institutions and structures. In terms of methodology, Blau believed that the unequal exchange had produced social power differences and stratification, which was different from Homans' interpretation of social exchange by the principle of reciprocity. For the detailed explanation, this article uses Blau's structural exchange theory as a theoretical support.

First, Blau made a distinction between social exchange and economic exchange. Economic exchanges are carried out in accordance with contractual contracts stipulated in the express text, and social exchanges generally impose obligations that are not specified. In addition, pure economic exchange does not lead to personal responsibility, gratitude and trust, while social exchange is just the opposite. At the same time, however, the benefits contained in social exchanges are not accurate in terms of prices and metrics. The value in exchanges is vague, which is also different from the gains and losses that can be accurately calculated and predicted in economic exchanges. Second, Blau also explained the rewards and expectations in the social exchange. Blau made three types of remuneration based on different criteria. One is the remuneration that can change hands in exchange, the second is the reward of internality and externality, and the third is the remuneration of mutuality and one-sidedness. Expectations are also divided into three categories, one is general expectations, the second is special expectations, and the third is comparative expectations, that is, the profits people get in social interactions. Finally, in terms of fairness, Blau and Hobbs basically maintained the same agreement. In general, the higher the cost and the higher the compensation, the higher the investment and the higher the profit.

In general, Blau's social exchange theory basically summarizes the characteristics of social exchange behavior in the micro-social structure. Next, this article will start with the theory of Blau and analyze the interpersonal relationship of college students.

\section{Characteristics and Problems of College Students' Interpersonal Communication-Taking Interpersonal Relationships in Intimate Relationships of College Students as an Example}

Through the nature of remuneration, Blau divided the remuneration in social exchange into two 
categories. One is the internal remuneration, that is, the remuneration obtained from the social interaction itself, such as fun, gratitude, social approval, etc.; the second is externality remuneration, that is, remuneration obtained outside of social relations, such as money, help, obedience, etc.

For the intimate relationship of college students, the form of the reward they receive is the intrinsic reward. A person who interacts with his object of love is based on intrinsic reward. Of course, the establishment of intimate relationships is the beginning in the early days of love. The internal rewards usually start from external rewards, which means that the interaction between lovers is often evaluated from the external image and family background. Blau also proposed that the relationship of love does have a comparative process at first, that is, comparing the looks, charms, and physiques of different objects, and gradually determining the relationship of love. This process shows that it is precisely to eliminate the comparison. Only when comparing different objects, the relationship that is finally established to exclude comparison is an intrinsic reward relationship [6]. However, for the group of college students, the characteristics of intrinsic remuneration should be more prominent, and the process of comparison is relatively insignificant.

However, in real life, it can be found that in the current rapid economic and social development, "love" has already left the "pure temple"." The trend of utilitarianization is obvious, and the shallow level of communication is an obvious feature. Under the influence of this trend, several problems of interpersonal communication of college students are exposed.

One is the self. Most of the contemporary college students are only children, and self-centered psychology has already formed and it is difficult to correct. There are not many college students with such psychology. This group is characterized by emphasizing the reasons for self-needs and never considering the needs and requirements of others. In the intimate relationship of college students, there is always a party in the relationship of love that is accustomed to arrogance. This relationship is actually morbid. From the perspective of social exchange theory, once the compensation paid by one party does not match the expectations of the other party, it will be difficult to maintain the intimate relationship in the long run.

The second is autism. The self-imposed isolation of most college students is to cover up their true thoughts, feelings and desires and try to be isolated from the world. Many college students pass the college entrance examination and come to the city from poverty-stricken areas. The gap in economic conditions makes their inferiority complex serious. Over time, they form autism. In addition, some students are accustomed to high school life, in addition to being proficient in learning, they are not trained to be human, and it is inevitable that they are not sociable. From the perspective of social exchange theory, this part of the population often lacks the "intrinsic remuneration" that can be given, and there are obvious intrinsic rewards that are difficult to meet the expectations of the other party.

The third is suspicion. Suspicion is an unfounded speculation or illusion that prevails on the basis of personal likes and dislikes. With the rapid development of the economy and society, suspicion in intimate relationships is no longer a case. This phenomenon is not uncommon among college students. As mobile phones carry more and more functions, the interpersonal communication of college students is more and more wide, and the objects of communication are diverse. It is no longer an unreasonable requirement for lovers to check mobile phones, and they are even used to it. But in fact, in many cases, the suspicion caused by mutual suspicion is shattered. However, this kind of tentative behavior has essentially destroyed the social exchange behavior between the two, making it from a fair social exchange to an unequal social exchange of information unequal.

\section{Corrective Ways of Negative Interpersonal Communication Model}

In real life, most college students can be rational and have rich interpersonal relationships. However, some of the more specific problems in the face of intimate relationships are that this group often makes some impulsive behaviors due to lack of experience and lack of experience in life. It is difficult to explain the social exchange theory. However, how to correct these negative interpersonal and interpersonal relationships can be explained by several basic propositions of social exchange. 


\section{Success proposition}

In an action done by a person, if one of the specific actions is often rewarded, the more likely the person is to repeat the action. According to this proposition, college teachers or counselors can correct the problems that arise in interpersonal communication by promptly guiding them to first have an objective evaluation of themselves, and then encourage them to participate in group activities, to experience a sense of accomplishment in participation, and timely encourage the ground to prevent the emergence of autistic and inferiority, and promptly carry out psychological self-regulation.

\section{Value proposition}

If the outcome of an action is more valuable to a person, the more likely the person is to do so. Parents and college teachers should let the college students clearly understand that the objective differences between people and people cannot be compared. Everyone has their own advantages and disadvantages, guiding college students to face themselves, and recognize their own values. Be aware of your own shortcomings and avoid the bipolar psychology of conceit and inferiority.

\section{Loss - satisfaction proposition}

If someone gets a particular reward in the near future, the subsequent reward will be less valuable to him. Treating the same college students cannot always reward or criticize the same characteristics. They should treat or carry out some "cold treatment" in many aspects.

All in all, the college student group is a group at a relatively special stage. It is too early to enter the society, but it can't be compared with the unsatisfactory situation in middle school. Paying attention to the analysis of college students' interpersonal skills has an extremely important role in their healthy growth and smooth entry into the society, and it deserves more people's attention.

\section{References}

[1] Chen Wei. Interpersonal Relationships of Contemporary College Students in the Perspective of Social Exchange Theory [J]. New Silk Road (30), 2016 (8): 60.(in Chinese)

[2] Cai Xuangguang. The Interpersonal Relationship of Contemporary Chinese Society from the Perspective of Social Exchange Theory [J]. Theoretical Observations, 2008 (3): 52-53. (in Chinese)

[3] WANG Cong-Cong, FU Chun-Xin. Research on Interpersonal Relationship of College Students' Dormitory from the Perspective of Social Exchange Theory [J]. Journal of Chifeng University (Chinese Philosophy and Social Sciences), 2015 (4): 223-224. (in Chinese)

[4] Li Qiang, Deng Weijian. The Guidance of College Counselors on College Students' Interpersonal Communication from the Perspective of Social Exchange Theory [J]. Education and Teaching Forum, 2011, Volume Missing (21): 85-86. (in Chinese)

[5] [United States] Jonathan H. Turner. The structure of sociological theory [M]. Wu Quhui et al (co-translation). Hangzhou: Zhejiang People's Publishing House, 1987.295. (in Chinese)

[6] Li Min, Zhang Xiaoshan. Western sociological theory, Huazhong University of Science and Technology Press, 2005, pp. 182-183. (in Chinese) 